\title{
Correction: Performance in delayed non-matching to sample task predicts the diagnosis of obsessive-compulsive disorder
}

Redwan Maatoug (D), Benoît Le Goff, Jean-Yves Rotge, Nemat Jaafari, Olivier Guillin and Bruno Millet

\section{Correction to: Translational Psychiatry https://doi.org/10.1038/s41398-019-0667-3 published online 10 December 2019}

The original Article contained a few errors in the author list. The given list was formally: "Maatoug R, Goff BL, Rotge JY, Jaafari PN, Guillin PO, Millet PB", when it should be "Maatoug R, Le Goff B, Rotge JY, Jaafari N, Guillin O, Millet B." This has been corrected in the XML, PDF and HTML versions of this Article. The publishers would like to apologise for this error.

Published online: 29 January 2020 